\title{
Bilateral Sudden Sensorineural Hearing Loss Associated with Sepsis: A Case Report and Literature Review
}

\author{
Hyun-Jin Lee ${ }^{1}$ D , Seong Ki Ahn ${ }^{2,3}$, Chae Dong Yim², and Dong Gu Hur ${ }^{3,4}$ \\ ${ }^{1}$ Department of Otorhinolaryngology-Head and Neck Surgery, Chung-Ang University College of Medicine, Seoul; and \\ ${ }^{2}$ Department of Otorhinolaryngology, Gyeongsang National University Hospital, Gyeongsang National University College of Medicine, \\ Jinju; and ${ }^{3}$ Institute of Health Sciences, Gyeongsang National University, Jinju; and \\ ${ }^{4}$ Department of Otorhinolaryngology, Gyeongsang National University Changwon Hospital, \\ Gyeongsang National University College of Medicine, Changwon, Korea
}

\author{
패혈증에서 기인한 양측성 돌발성 난청 1예

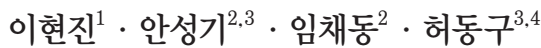 \\ 1중앙대학교 의과대학 이비인후과학교실, ${ }^{2}$ 경상국립대학교 의과대학 경상국립대학교병원 이비인후과학교실, \\ ${ }^{3}$ 경상국립대학교 건강과학연구원, ${ }^{4}$ 경상국립대학교 의과대학 창원경상국립대학교병원 이비인후과학교실
}

\author{
Received January 18, 2021 \\ Revised April 6, 2021 \\ Accepted May 10, 2021 \\ Address for correspondence \\ Hyun-Jin Lee, MD \\ Department of Otorhinolaryngology- \\ Head and Neck Surgery, \\ Chung-Ang University \\ College of Medicine, \\ 84 Heukseok-ro, Dongjak-gu, \\ Seoul 06974, Korea \\ Tel +82-2-6299-1765 \\ Fax $+82-2-825-1765$ \\ E-mail eenigma35@gmail.com
}

Bilateral sudden sensorineural hearing loss (SSNHL) is rare and usually indicates a serious systemic pathology. We describe an unusual case of bilateral SSNHL caused by sepsis. A 28-year-old female complained of acute-onset bilateral hearing impairment; in addition to otological symptoms, she had a systemic condition that met the criteria for sepsis. We performed a physical examination and laboratory tests to diagnose sepsis. Pure tone audiogram and videonystagmography were performed to evaluate the otological symptoms. Intravenous antibiotics and high-dose methylprednisolone were prescribed for treatment, and audiogram was repeated during that period. The fever subsided and the vital signs were stabilized. The electrolyte imbalance and abnormal urine parameters became normal. Hearing gradually recovered to a normal level on day 7 of hospitalization. In conclusion, sepsis should be considered as a cause of SSNHL. When conducting a detailed examination of patients with bilateral SSNHL, the clinician should consider systemic disease.

Korean J Otorhinolaryngol-Head Neck Surg 2021;64(9):674-9

Keywords Antibiotics; Bilateral hearing loss; Hearing loss, sudden; Sepsis; Steroid.

\section{Introduction}

Sudden sensorineural hearing loss (SSNHL) is defined as hearing loss of more than $30 \mathrm{~dB}$ at three continuous frequencies that develops in less than 3 days. ${ }^{1)}$ The annual incidence ranges from 5-27 per 100000 of the population. ${ }^{2)}$ Most cases are idiopathic; other proposed causes include viral infection, vascular compromise, autoimmune disease, and labyrinthine

This is an Open Access article distributed under the terms of the Creative Commons Attribution Non-Commercial License (https://creativecommons.org/licenses/by-nc/4.0) which permits unrestricted non-commercial use, distribution, and reproduction in any medium, provided the original work is properly cited. membrane rupture. ${ }^{3)}$ Bilateral SSNHL is rarer, representing less than $4.9 \%$ of all cases, and appears not to be idiopathic but rather to reflect a serious systemic pathology. Also, bilateral SSNHL has a poorer prognosis than unilateral SSNHL. ${ }^{4}$ Of the possible causes, bacterial infection is rare, but can be fatal. Moreover, sepsis is a very rare systemic bacterial infection, and to the best of our knowledge it has never been reported to cause bilateral SSNHL. Most reported bacterial etiologies have been meningitis or infective endocarditis. Eden and Cummings $^{5)}$ reported two cases of bilateral SSNHL as complications of bacterial meningitis, and Lau, et al. ${ }^{6}$ reported a 
case caused by Staphylococcus endocarditis. Recently, in a report of two cases, Chroni, et al. ${ }^{7)}$ suggested that septic emboli might possibly cause bilateral SSNHL. Sepsis is defined as a life-threatening organ dysfunction caused by a dysregulated host response to infection. ${ }^{8)}$ Cellular reactions and circulatory dysfunctions triggered by invading pathogens may cause multi-organ dysfunction, and can thus damage the inner ear. Additionally, because sepsis is a systemic disease, the inner ear can be affected bilaterally, causing SSNHL. Herein, we report a rare case of bilateral SSNHL induced by sepsis and the possible mechanisms involved.

\section{Case}

A 28-year-old female visited our outpatient clinic with bi- lateral hearing loss that had developed 3 days prior. She was mentally alert but reported whirling vertigo. Her body temperature at the time of the visit was $38.7^{\circ} \mathrm{C}$, and she reported a fever that had persisted for the past 5 days. Her medical, surgical, and family history were otherwise unremarkable. We found no upper respiratory or gastrointestinal symptom, but left costovertebral angle tenderness and dysuria were evident. On endoscopic examination, both eardrums were normal the pure tone thresholds were $49 \mathrm{~dB}$ on the right and $45 \mathrm{~dB}$ on the left, evidencing moderate sensorineural hearing loss. The speech recognition thresholds (SRTs) were $48 \mathrm{~dB}$ on the right and $46 \mathrm{~dB}$ on the left. Videonystagmography revealed no abnormal nystagmus except for subtle upbeat nystagmus on the lean test, left roll test, and both Dix-Hallpike tests, and the caloric response was within the normal range. The video head

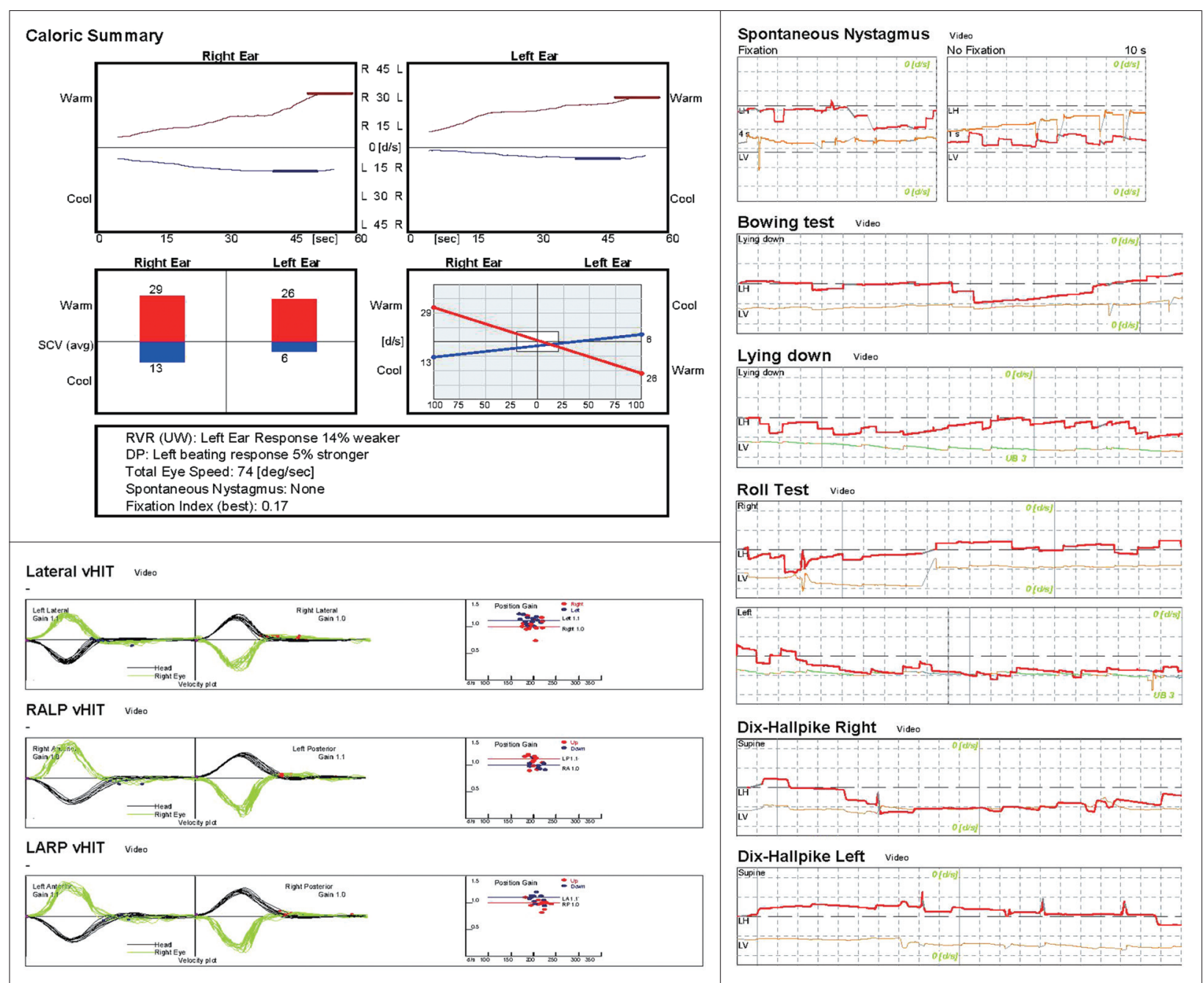

Fig. 1. Results of the vestibular function test. The caloric response was within the normal range. Videonystagmography revealed no specific abnormal nystagmus, but subtle upbeat nystagmus was observed on the lean test, the left roll test, and both Dix-Hallpike tests, suggesting that the posterior canal may have been affected. The vHIT showed no abnormal saccades and the vestibulo-ocular reflex gains were normal. vHIT, video head impulse test. 
impulse test showed no abnormal saccades, and the vestibulo-ocular reflex gains were found to be normal (Fig. 1). After diagnosing bilateral SSNHL, the patient was hospitalized for further examination and treatment. On admission, her vital signs included a low blood pressure $(92 / 63 \mathrm{~mm} \mathrm{Hg})$, a high pulse rate (123 beats/min), and an upper-normal respiratory rate (20 breaths/min). Serological tests revealed that the peripheral white blood cell (WBC) count was $30.60 \times 10^{3} / \mu \mathrm{L}$, the hemoglobin $(\mathrm{Hb})$ level $8.4 \mathrm{~g} / \mathrm{dL}$, and the platelet count $88 \times 10^{3} / \mu \mathrm{L}$. The $\mathrm{C}$-reactive protein (CRP) level was elevated to $96.3 \mathrm{mg} / \mathrm{L}$, and the erythrocyte sedimentation rate (ESR) was $117 \mathrm{~mm} / \mathrm{h}$. Other laboratory tests indicated liver dysfunction, an electrolyte imbalance, and abnormal urine (Table 1). Escherichia coli was detected in a blood culture that was scheduled because of the persistent high fever. These findings meet the criteria for sepsis. Because dysuria and left costovertebral angle tenderness were present, we suspected that left acute pyelonephritis was the cause of sepsis. Treatment proceeded after consultation with the internal medicine department. Intravenous ceftriaxone ( $2 \mathrm{~g} \mathrm{q} 24 \mathrm{~h}$ ) was given before blood culture, and intravenous ciprofloxacin (400 mg q12 h) was maintained for 2 weeks after the culture results were confirmed. The fever gradually decreased and the heart rate recovered to a normal level, and the hearing and dizziness gradually improved. On day 4 of hospitalization, after the culture results were confirmed and the antibiotics were changed, the fever subsided and the systolic blood pressure was maintained above $100 \mathrm{~mm} \mathrm{Hg}$. Also, the dizziness resolved and the nystagmus completely disappeared. The electrolyte imbalance returned to normal after correction, as did the urine analysis (Table 1). The patient had been placed on high-dose methylprednisolone (48 mg q24 h) to treat the SSNHL from day 1 of hospitalization. As her general condition improved, her hearing gradually recovered to within the normal range on day 7 of hospitalization (Fig. 2). After consultation with the internal medicine department, the steroid was stopped early after confirming that hearing had been restored, and the patient was discharged after the end of antibiotic treatment. She is currently undergoing follow-up; no hearing loss or other abnormality has developed over 3 months from the date of hospitalization.

\section{Discussion}

The initial definition of sepsis was developed at a 1992 consensus conference and was based on the systemic inflammatory response syndrome (SIRS). ${ }^{9)}$ SIRS must fulfil at least two
Table 1. Clinical and laboratory characteristics of the patient

\begin{tabular}{|c|c|c|c|c|}
\hline & \multicolumn{3}{|c|}{ Patient } & \multirow{2}{*}{$\begin{array}{l}\text { Normal } \\
\text { value }\end{array}$} \\
\hline & Initial & Day\#3 & Day\#7 & \\
\hline Age (year) & 28 & & & \\
\hline Sex & Female & & & \\
\hline Height (cm) & 150.6 & & & \\
\hline Weight (kg) & 47.8 & & & \\
\hline \multicolumn{5}{|l|}{$A B G A$} \\
\hline $\mathrm{pH}$ & 7.51 & & & $7.35-7.45$ \\
\hline $\mathrm{pCO}_{2}(\mathrm{~mm} \mathrm{Hg})$ & 34 & & & $32-46$ \\
\hline $\mathrm{pO}_{2}(\mathrm{~mm} \mathrm{Hg})$ & 108 & & & $80-90$ \\
\hline Bicarbonate $(\mathrm{mmol} / \mathrm{L})$ & 27 & & & $23-29$ \\
\hline $\mathrm{O}_{2}$ saturation $(\%)$ & 98.1 & & & $94.0-100.0$ \\
\hline \multicolumn{5}{|l|}{ Laboratory findings } \\
\hline $\operatorname{WBC}\left(10^{3} / \mu \mathrm{L}\right)$ & 30.60 & 19.30 & 12.43 & $4.00-10.00$ \\
\hline Neutrophil (\%) & 82.6 & 78.2 & 76.8 & $50.0-75.0$ \\
\hline Hemoglobin (g/dL) & 8.4 & 8.8 & 9.5 & $12.0-16.0$ \\
\hline Platelet $\left(10^{3} / \mu \mathrm{L}\right)$ & $88^{*}$ & 265 & 342 & $130-400$ \\
\hline $\operatorname{ESR}(\mathrm{mm} / \mathrm{hr})$ & 117 & 90 & 61 & $0-20$ \\
\hline CRP (mg/L) & 96.3 & 31.9 & 9.8 & $0.0-5.0$ \\
\hline $\mathrm{Na}(\mathrm{mmol} / \mathrm{L})$ & 123.2 & 132.7 & 136.5 & $136.0-146.0$ \\
\hline $\mathrm{K}(\mathrm{mmol} / \mathrm{L})$ & 2.7 & 4.5 & 4.1 & $3.5-5.1$ \\
\hline $\mathrm{Cl}(\mathrm{mmol} / \mathrm{L})$ & 81.4 & 100.2 & 106.0 & $101.0-109.0$ \\
\hline Bilirubin (mg/dL) & $2.38^{*}$ & 1.08 & 0.72 & $0.30-1.20$ \\
\hline AST (U/L) & 70 & 49 & 28 & $1-37$ \\
\hline $\operatorname{ALT}(\mathrm{U} / \mathrm{L})$ & 32 & 28 & 16 & $0-41$ \\
\hline BUN (mg/dL) & 14.6 & 10.3 & 8.9 & $8.0-20.0$ \\
\hline Creatinine (mg/dL) & 0.78 & 0.55 & 0.58 & $0.51-0.95$ \\
\hline \multicolumn{5}{|l|}{ Urine analysis } \\
\hline Urine WBC (/HPF) & $>100$ & $50-99$ & $20-29$ & $0-4$ \\
\hline Urine bilirubin & $1+$ & - & - & - \\
\hline Urine urobilinogen & $2+$ & - & - & - \\
\hline
\end{tabular}

* findings included in the criteria of sepsis. ABGA, arterial blood gases analysis; $\mathrm{PCO}_{2}$, partial pressure of carbon dioxide; $\mathrm{PO}_{2}$, partial pressure of oxygen; WBC, white blood cell; ESR, erythrocyte sedimentation rate; CRP, C-reactive protein; $\mathrm{Na}$, sodium; K, potassium; Cl, chloride; AST, aspartate transaminase; ALT, alanine transaminase; BUN, blood urea nitrogen

of the following four criteria: body temperature $>38^{\circ} \mathrm{C}$ or $<36^{\circ} \mathrm{C}$, heart rate $>90$ beats $/ \mathrm{min}$, respiratory rate $>20 / \mathrm{min}$ or a $\mathrm{PaCO}_{2}<32 \mathrm{~mm} \mathrm{Hg}$, and a WBC count $>12000 / \mathrm{mm}^{3}$ or $<4000$ $/ \mathrm{mm}^{3}$. Sepsis requires both a confirmed or suspected infection and SIRS. However, this initial definition did not explain the pathophysiology of sepsis, and was inadequately sensitive and specific. Many revisions have since been attempted. The most recent sepsis criteria were published as 'Sepsis-3,' a consensus guideline published by the European Society of Intensive Care Medicine and the Society of Critical Care Medicine in 2016. ${ }^{8)}$ This guideline defines sepsis based on the sequential organ failure assessment (SOFA) score (a conventional score 


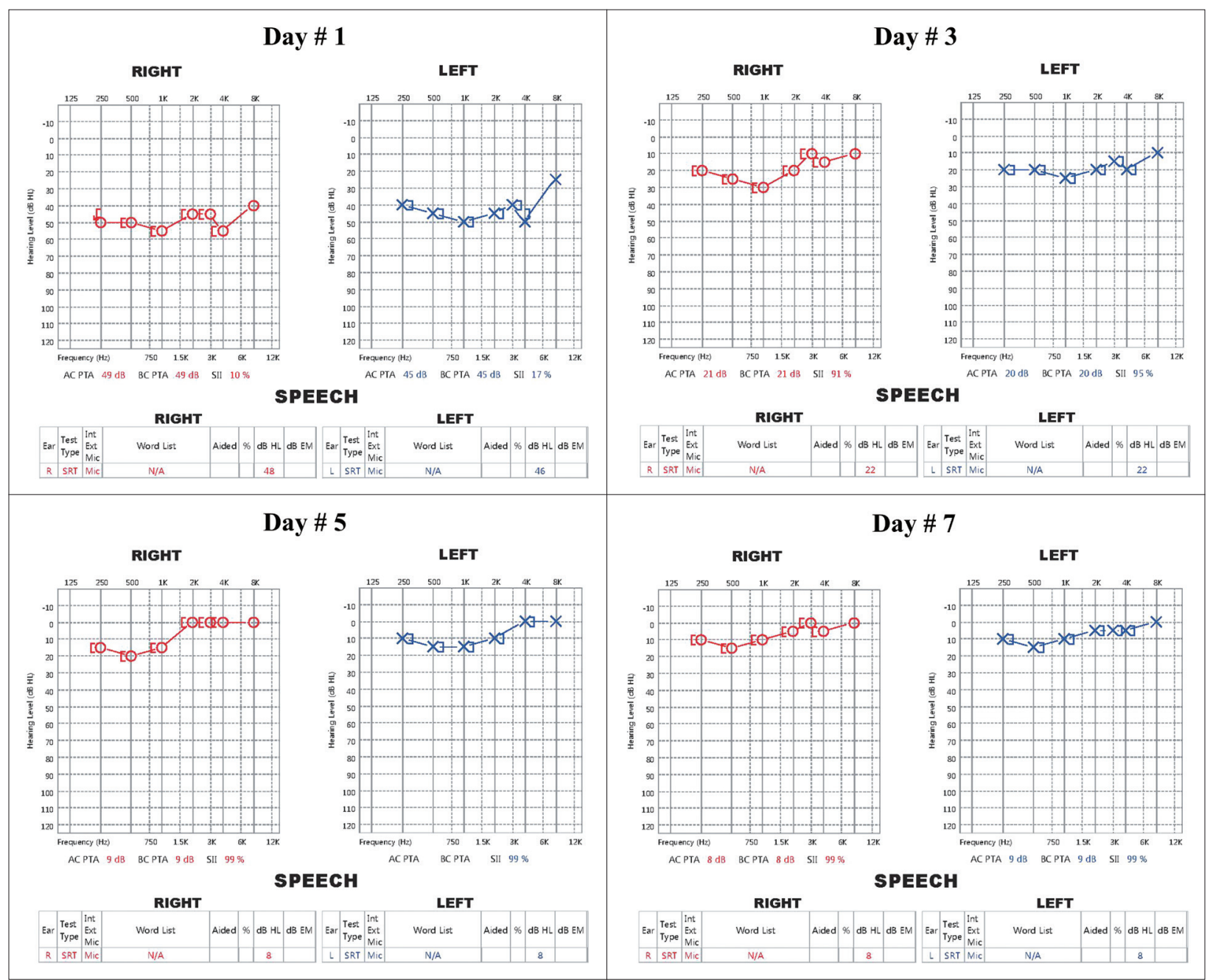

Fig. 2. Sequential pure tone audiograms. The audiogram taken at the time of diagnosis revealed moderate, bilateral symmetrical SNHL. During treatment, the SNHL of both ears improved gradually as the general condition improved. The hearing improvements were symmetrical; the high frequencies recovered faster than the low frequencies. On day 7 of hospitalization, both ears evidenced near-normal hearing. SRT results did not differ significantly from the pure tone thresholds. SNHL, sensorineural hearing loss; SRT, speech recognition threshold.

predicting the prognosis of critically ill patients); specifically as an increase of $\geq 2$ points. ${ }^{10)}$ In our patient, fever and increased WBC count were no longer included in the diagnostic criteria and her blood pressure did not meet the criterion, in contrast to the initial definition. However, the abnormal bilirubin and platelet data were worth 4 points on the SOFA score and a pathogen was clearly identified, so sepsis could be diagnosed.

To date, no clear association has been identified between bilateral SSNHL and sepsis, but several reports have mentioned the possibility. Schmutzhard, et al. ${ }^{11)}$ reported that experimental sepsis caused hearing impairment of the murine cochlea, and in a long-term study Cheng, et al. ${ }^{12)}$ observed hearing impairments in septicemia survivors, although these cases did not involve sudden onset. In our case, the systemic symptoms and hearing loss coincided. Additionally, improvements in the fever and the abnormal laboratory findings paralleled the hearing recovery. Therefore, the systemic septic condition may have been closely related to the hearing impairment in our patient.

As the general condition of our patient was poor, it was necessary to rule out the possibility of malingering or psychogenic hearing loss when diagnosing bilateral SSNHL. In such a case, objective hearing tests such as the auditory brainstem response (ABR) or auditory steady-state response test should be considered. We planned to perform the ABR test, but did not in fact do so because hearing recovered earlier than expected. However, as the SRT results did not differ significantly from the pure tone thresholds, and as the sequential pure tone audiograms were consistent, the hearing results are considered to be reliable. 
Several mechanisms have been proposed to explain SSNHL induced by sepsis. The first is a regional ischemic change caused by microcirculatory dysfunction. Sepsis is a complex pathophysiological process involving both microcirculatory alterations and changes in the biochemical and physiological characteristics of blood constituents. ${ }^{13)}$ Such alterations may trigger microvascular changes that affect the blood supply to and oxygenation of the cochlea. Arterial hypotension, blood loss and anemia, the prone position, and venous congestion may also play roles. The cochlea is a highly metabolic organ and is susceptible to ischemic changes because it only receives blood from the terminal artery. Therefore, microcirculatory alterations in a septic patient may increase the risk of SSNHL. Septic emboli may also cause hearing loss by inducing ischemic changes in the internal auditory artery that supplies the inner ear. Septic emboli are caused principally by infections developing after invasive procedures, endocarditis, or deep vein thrombosis, and may thus not be the cause of the SSNHL of our patient. Finally, an infection may spread directly to the inner ear. The causative pathogen may reach peripheral organs via hematological spread. When bacteria directly invade the cochlea, the resulting labyrinthitis may trigger cochlear dysfunction and SSNHL. These proposed mechanisms may explain why SSNHL was bilateral in our patient, and this case is consistent with previous reports suggesting that bilateral SSNHL is more closely associated with systemic disease than unilateral SSNHL. Because the bilateral hearing loss of our patient was reversible and not profound, the mechanism in play may involve microcirculatory alterations and septic emboli rather than direct bacterial invasion. Such changes affect not only the cochlea, but also the vestibular organs. The subtle upbeat nystagmus may be attributable to an effect on the posterior canal, which shares its terminal vascular supply with the cochlea. It is important to note that although sepsis patients rarely visit hospital with hearing loss as a main symptom, such loss remains possible in young healthy patients without underlying disease. Therefore, in patients with bilateral SSNHL, it is necessary to consider a possible underlying systemic disease.

The use of antibiotics was essential in our patient, because the bilateral SSNHL was triggered by sepsis. However, the use of steroids is controversial. Lefering and Neugebauer ${ }^{14)}$ reported that steroids were appropriate for patients with gram-negative septicemia, and a recent study found that corticosteroid therapy significantly improved the outcomes (and reduced the mortality) of patients with sepsis. ${ }^{15)}$ Many studies have shown that steroids aid recovery from SSNHL. Therefore, the use of steroids in patients with sepsis is worth considering after consultation with an internal medicine specialist.

Based on our experience and literature review, sepsis should be considered as a possible cause of SSNHL, particularly bilateral SSNHL. When conducting a detailed examination of patients with bilateral SSNHL, the clinician should consider the possibility of an underlying systemic disease.

\section{Acknowledgments}

None.

\section{Author Contribution}

Conceptualization: all authors. Formal analysis: Seong Ki Ahn. Funding acquisition: Chae Dong Yim. Investigation: Seong Ki Ahn, Dong Gu Hur. Resources: Chae Dong Yim. Supervision: Seong Ki Ahn. Validation: Chae Dong Yim. Visualization: Dong Gu Hur. Writing — original draft: Hyun-Jin Lee, Chae Dong Yim. Writingreview \& editing: Dong Gu Hur.

\section{ORCID}

Hyun-Jin Lee https://orcid.org/0000-0001-7472-830X

\section{REFERENCES}

1) Chandrasekhar SS, Tsai Do BS, Schwartz SR, Bontempo LJ, Faucett EA, Finestone SA, et al. Clinical practice guideline: Sudden hearing loss (update). Otolaryngol Head Neck Surg 2019;161(1_ suppl):S1-45.

2) Alexander TH, Harris JP. Incidence of sudden sensorineural hearing loss. Otol Neurotol 2013;34(9):1586-9.

3) Chau JK, Lin JR, Atashband S, Irvine RA, Westerberg BD. Systematic review of the evidence for the etiology of adult sudden sensorineural hearing loss. Laryngoscope 2010;120(5):1011-21.

4) Sara SA, Teh BM, Friedland P. Bilateral sudden sensorineural hearing loss: Review. J Laryngol Otol 2014;128 Suppl 1:S8-15.

5) Eden AR, Cummings FR. Sudden bilateral hearing loss and meningitis in adults. J Otolaryngol 1978;7(4):304-9.

6) Lau JW, Ceranic B, Harris R, Timehin E. Bilateral sudden sensorineural hearing loss in Staphylococcus aureus endocarditis. BMJ Case Rep 2015;2015:bcr2015211700.

7) Chroni M, Prappa E, Kokkevi I. Bilateral sudden sensorineural hearing loss as a first symptom of infective endocarditis: Two case reports. J Laryngol Otol 2018;132(4):368-71.

8) Singer M, Deutschman CS, Seymour CW, Shankar-Hari M, Annane $\mathrm{D}$, Bauer $\mathrm{M}$, et al. The third international consensus definitions for sepsis and septic shock (Sepsis-3). JAMA 2016;315(8):801-10.

9) Bone RC, Balk RA, Cerra FB, Dellinger RP, Fein AM, Knaus WA, et al. Definitions for sepsis and organ failure and guidelines for the use of innovative therapies in sepsis. The ACCP/SCCM Consensus Conference Committee. American College of Chest Physicians/ Society of Critical Care Medicine. Chest 1992;101(6):1644-55.

10) Vincent JL, Moreno R, Takala J, Willatts S, De Mendonça A, Bruining $\mathrm{H}$, et al. The SOFA (sepsis-related organ failure assessment) score to describe organ dysfunction/failure. On behalf of the working group on sepsis-related problems of the European Society of Intensive Care Medicine. Intensive Care Med 1996;22(7): 707-10.

11) Schmutzhard J, Glueckert R, Pritz C, Blumer MJ, Bitsche M, Lackner $\mathrm{P}$, et al. Sepsis otopathy: Experimental sepsis leads to significant hearing impairment due to apoptosis and glutamate excitotoxicity 
in murine cochlea. Dis Model Mech 2013;6(3):745-54.

12) Cheng CG, Chien WC, Lin HC, Lin $\mathrm{HC}$, Chung $\mathrm{CH}$, Cheng CA. Hearing impairment in young and middle-aged septicemia survivors. Medicine (Baltimore) 2020;99(29):e21050.

13) Piagnerelli M, Boudjeltia KZ, Vanhaeverbeek M, Vincent JL. Red blood cell rheology in sepsis. Intensive Care Med 2003;29(7):105261.
14) Lefering R, Neugebauer EA. Steroid controversy in sepsis and septic shock: A meta-analysis. Crit Care Med 1995;23(7):1294-303.

15) Fang F, Zhang Y, Tang J, Lunsford LD, Li T, Tang R, et al. Association of corticosteroid treatment with outcomes in adult patients with sepsis: A systematic review and meta-analysis. JAMA Intern Med 2019;179(2):213-23. 